\title{
EDitorial
}

\section{O Futuro com a Medicina de Precisão}

O termo “Precision Medicine”, ou 'Medicina de precisão', começou a ser utilizado de forma ampla a partir de janeiro de 2015 com o lançamento da "Precision Medicine Initiative" pelo então presidente Barack Obama. Essa nova terminologia objetiva classificar as novas abordagens na área de saúde que consideram as diferenças moleculares, epigenéticas e ambientais que geram diferentes respostas a uma mesma classe de medicamentos, viabilizando a escolha e desenvolvimento de medidas terapêuticas mais efetivas.

A diferença para a medicina personalizada é que esta se relaciona, pela definição do termo, a uma abordagem individualizada com medicamentos desenvolvidos exclusivamente para um determinado paciente, enquanto que a medicina de precisão pretende entender a resposta de determinadas subpopulações, utilizando dados como expressão gênica e apresentação clínica, para a prescrição da melhor terapêutica. Sabe-se que, no caso de câncer de pulmão, cada mutação associada com a neoplasia tem maior prevalência em algumas subpopulações, sendo determinante na escolha de medicamentos imunoterápicos, o que torna possível um tratamento com boa resposta e alta especificidade.

A medicina de precisão não se resume somente ao campo de desenvolvimento de drogas para tratamento de condições clínicas. A fisiopatologia de algumas doenças pode ser entendida por meio do estudo da expressão gênica que indivíduos com a mesma exposição ambiental apresentam. Como exemplo, as alterações epigeneticas que combatentes norte americanos sofrem na zona de conflito que levariam à diminuição da expressão de receptores de glicocorticóides no hipotálamo e, portanto, a um estado de estresse prorrogado, poderiam estar na gênese do transtorno de estresse pós traumático, tão frequente nessa subpopulaçao.

Além de promoção de pesquisas que visem a essa abordagem molecular, várias iniciativas têm como foco organizar e unificar bases de dados para que haja uma interligação entre as pesquisas e os dados clínicos de vários centros com o intuito de a informação gerada nas pesquisas possam chegar na clínica rapidamente. E, também, para que os dados obtidos em diversas pesquisas possam ser usados em novas com uma amostra cada vez maior, possibilitando, assim o desenvolvimento de tratamentos mais precisos. A "California Initiative to Advance Precision Medicine" é um exemplo de parceria das instituições públicas e particulares que está financiando a construção de um centro unificado para armazenar as informações médicas e os dados gerados em pesquisas no estado. 
Esse novo modelo de abordagem das informações obtidas em cada consulta, exame e estudo poderá propiciar um cenário no qual todos os bytes de informações geradas, desde o nascimento, sejam armazenados e interconectados, possibilitando, assim, a formação de coortes regionais, nacionais e, até mesmo, mundiais. Com certeza, teremos que, nos próximos anos, discutir inúmeras questões éticas sobre a responsabilidade pelos dados de cada paciente, sobre consentimentos amplos para pesquisas sem projetos ainda aprovados e, também, autoria de pesquisas usando dados de outras. Porém, é uma evolução que já está em andamento.

\section{Viktor Sinkunas}

Editor chefe da Revista de Medicina

\section{Guilherme Yuiti Sikusawa}

Editor Executivo da Revista de Medicina

\section{Jose Otavio Costa Auler Junior}

Diretor da Faculdade de Medicina FMUSP, Universidade de Sao Paulo 